\title{
Explaining the Risk Factors Increase in Cardiovascular Disease Mortality in Chinese Patients
}

\author{
Jie Zhang*1,2, Hongwei Yan', Longbin Ren ${ }^{1,2}$, Jingjing Chen ${ }^{1,2}$, Zhe Mu $^{3}$, Li Peng ${ }^{3}$, Lijuan Zhang ${ }^{1,2}$ and Jue \\ $\mathrm{Li}^{1,2}$ \\ ${ }^{1}$ Shanghai East Hospital, Tongji University School of Medicine, China
}

${ }^{2}$ Institute of Clinical Epidemiology and Evidence - based medicine, Tongji University School of Medicine, China

${ }^{3}$ Shanghai Key Laboratory of Meteorology and Health, China

Received: May 28, 2018; Published: June 11, 2018

*Corresponding author: Jie Zhang, Shanghai East Hospital, Key Laboratory of Arrhythmias, Ministry of Education, Tongji University School of Medicine, Shanghai 200120, China

\begin{abstract}
Cardiovascular disease (CVD) mortality is rising in many developing countries. There are many reasons for the mortality. In this study, we applied the IMPACT model to examine how much of the increase in CVD mortality in Beijing and Shanghai, two biggest cities in China. Also, we explored the changes of cardiovascular disease risk factors and assessed the influence of medication treatments on CVD mortality. The patients were enrolled from 2004 to 2010. The result showed that there was an increasing mortality rate of CVD by a negative age gradient in men and women after 45 years old. Most of the prevalence of CVD in different risk factor groups had an increased trend from 2008 to 2010, such as high blood pressure (BP), diabetes mellitus (DM), stoke, peripheral arterial disease (PAD) and coronary heart disease (CHD). From 2004 to 2010, medical treatments in individuals together prevented or postponed almost 205 deaths in 2010. Substantial contributions came from treats of ACEI (26\%), CCP (25\%), Statins (23\%), beta-receptor blocker (17\%) and Diuretic (9\%). Due to a few numbers of eligible patients who took Fibrates, there was $0 \%$ DPPs. The model fit results were good in BP and DM groups.
\end{abstract}

Keywords: Cardiovascular disease; ACEI; IMPACT model; Mortality

\section{Introduction}

In China, due to the rapid economic development, the national living standard has a very big improvement. And the health care services have been enhanced rapidly. At the meanwhile, there are some apparently changes in lifestyle and diet in some big cities, especially in Beijing andShanghai. An increasing "western" diet includes an increase in consumption of red meat eggs and oils and declines in fruit and vegetable intake [1-5]. Also, people always have high work stress and lack of physical exercise. All of this led an increasing prevalence of cardiovascular disease (CVD). These CVD trends are consistent with the risk factor paradigm. Evidence supports a causal association with the major CVD risk factors: cholesterol, blood pressure, smoking and physical inactivity [68]. Also, the IMPACT model has been applied in many developed countries, particularly the United States, Netherlands, New Zealand, and United Kingdom, suggest that 55\% to $65 \%$ of recent, substantial coronary heart disease (CHD) mortality declines can be attributed to declines in major risk factors, the remainder being attributable to medical and surgical treatments [6,9-13].

In 2004, there was a study to explaining the increase in CHD mortality in Beijing between 1984 and 1999 which was applied the IMPACT model successfully [14]. However, in that study many data source was not from their own cohort study but from other researchers' published data source or meta-analysis. Different with Julia et.al work [14], we focused on some disease risk factors for CVD, such as Diabetes, Hypertension, CHD, PAD and Stroke and the medicine treatments (Blood lipid treatment and Hypertension treatment), which was launched in our own cohort study. The samples in our study were enrolled in hospital which ensured a high follow up.

\section{Materials and Methods}

In our study, we applied the IMPACT model in medication usage. The IMPACT mortality model, validated in Scotland [10], New Zealand [9], China [14], Finland, and England and Wales [13], was further developed and refined.

\section{Dataset Sources}

Subjects over 35 years old were recruited from the endocrinology or cardiology in-patient clinic at 8 university hospitals in Beijing and Shanghai from July to November 2004. Risk factors included diabetes mellitus (DM), hypertension, dyslipidemia, stroke and 
history of coronary artery disease. Exclusion criteria included severe heart failure, liver failure, renal failure and cancer. Finally, a population of 3179 patients, aged $\geq 35$ years, including 1707 men and 1472 women who had complete baseline data, were entered in the cohort. They were followed up until an end point (death) was reached or until November 2010. This study was approved by the ethics committee of Tongji University and informed consent was obtained from the participants.

\section{Definitions}

Participants were diagnosed as hypertension if their systolic or diastolic readings were consistently higher than 120/80 mmHg, reported use of hypertension medicine, or had hypertension at the baseline examination. Participants were diagnosed as diabetic if they had fasting plasma glucose (FPG) $\geq 7 \mathrm{mmol} / \mathrm{L}$, reported use of hypoglycemic medication, or had DM at the baseline examination. An $\mathrm{ABI} \leq 0.9$ in either leg was considered as evidence of PAD. Participants were diagnosed as Stroke or CHD if they had stroke or CHD at the baseline examination respectively. The status of participants would be renewed after follow up. Death was identified by hospitals records or by contacting the participants' families. Further causes of death were investigated by using medical records and informant interviews. All materials were reviewed independently by a physician of the cohort study to confirm the cause of death. CVD death is defined as death due to coronary heart disease or stroke.

\section{Information of Relevant Data}

Information on prevalence, treatment and mortality were based on the cross-sectional data in 2004 and cohort data from 2006 to 2010. Information on treatment prescription and uptake was obtained from our survey above.

\section{The Impactmodels}

Risk Factor Trends and Mortality Change: The risk factors were dichotomized and population attributable risk fraction (PAR) was calculated which was based on relative risk (RR), as follows. RRs were obtained from a dichotomized risk factor and patient prevalence. The number of CVD deaths expected in 2008 if 2006 mortality rates had persisted was calculated. The number of CVD deaths expected in 2010 if 2008 mortality rates had persisted was calculated. Each of compared with the CVD deaths observed in 2008 and 2010 respectively, to yield the increase in CVD deaths between 2006 to 2008 and 2008 and the increase in CVD deaths between 2008 to 2010, by age and gender. The mortality change expected from trends in different cardiovascular histories, such as high blood pressure (BP), diabetes mellitus (DM), stoke, peripheral arterial disease (PAD) and coronary heart disease (CHD).

$$
P A R=\frac{\text { Prevalence } \times(\text { Relative Risk }-1)}{(\text { Prevalence } \times(\text { Relative Risk }-1))+1}
$$

Medical Treatment: The model aimed to include the medical treatments in the patients enrolled. The mortality reduction for each treatment, stratified by age and gender, was calculated as the relative mortality reduction reported in published meta-analyses multiplied by the age-specific case fatality observed in that group. Case-fatality data came from the Beijing MONICA study and from large, unselected, population-based patient cohorts [15]. Survival benefit over a 1-year time interval was used for all treatments.

Death Prevented or Postponed in 2008 and 2010: The detail medical treatments were followed in each visit; however, just few drugs were same in the whole three visits, 2006, 2008 and 2010. This bias limited the IMPACT model building and we could not get a comprehensive result for treatments.

Model Validation: The model estimate for the changes in deaths attributed to all treatments plus all risk factor changes was summed and then compared with the observed increases in mortality for men and women in each specific age group.

Other Statistical Analysis: Continuous variable, such as age, was presented as mean \pm s.d., categorical variables were expressed as a percentage. Participants were classified into subgroups according to sex and age.Independent samples ANOVA (analysis of variance) and the $\div 2$-test were used to compare continuous and categorical differences at baseline. A p-value of $<0.05$ was considered significant. All analyses were performed with SPSS (Statistics Package for Social Science) version 20.0 and R version 3.4.1.

\section{Results}

In Beijing and Shanghai from 2006 to 2008, CVD mortality rates increased largely by $107.14 \%$ in men and $100.00 \%$ in women aged 50 to 64. (Table 1; 526933 more CVD deaths than expected from baseline mortality rates in 2006). Except a lowest rate in aged 35 to 49 years, the increase in mortality rates showed a negative age gradient in men and women after age 45, decreasing from $107.14 \%$ among those aged 50 to 64 years to $45.45 \%$ in those aged more than 80 years, and a similar gradient in women, with decrease of $100.00 \%, 86.84 \%$ and $84.21 \%$ in the respective age groups.

Table 1: Patients groups and death rate to all-cause.

\begin{tabular}{|c|c|c|c|c|c|c|c|c|c|}
\hline & \multicolumn{4}{|c|}{ Men, Age Group, y } & \multicolumn{4}{|c|}{ Women, Age Group, y } & \multirow[t]{2}{*}{$\mathbf{p}$} \\
\hline & $35-49$ & $50-64$ & $65-79$ & $80 \sim$ & $35-49$ & $50-64$ & $65-79$ & $80 \sim$ & \\
\hline $\begin{array}{l}\text { Patients } \\
\text { size, } n\end{array}$ & 158 & 451 & 891 & 207 & 78 & 417 & 821 & 156 & $<0.0005$ \\
\hline \multicolumn{10}{|c|}{ All cause-Deaths, $n$} \\
\hline 2006 & 8 & 16 & 99 & 59 & 5 & 16 & 63 & 34 & $<0.0005$ \\
\hline 2008 & 10 & 53 & 163 & 90 & 9 & 34 & 128 & 56 & $<0.0005$ \\
\hline 2010 & 20 & 81 & 265 & 125 & 12 & 54 & 208 & 76 & $<0.0005$ \\
\hline
\end{tabular}




\begin{tabular}{|c|c|c|c|c|c|c|c|c|c|}
\hline \multicolumn{10}{|c|}{ All cause-Deaths increase,\% } \\
\hline 2008 & 25.00 & 231.25 & 64.65 & 52.54 & 80.00 & 112.50 & 103.17 & 64.71 & \\
\hline 2010 & 150.00 & 406.25 & 167.68 & 111.86 & 140.00 & 237.50 & 230.16 & 123.53 & \\
\hline \multicolumn{10}{|c|}{ CVD death, $n$} \\
\hline 2006 & 6 & 14 & 66 & 33 & 3 & 10 & 38 & 19 & $<0.0005$ \\
\hline 2008 & 7 & 29 & 96 & 48 & 4 & 20 & 71 & 35 & $<0.0005$ \\
\hline 2010 & 14 & 39 & 133 & 62 & 4 & 29 & 107 & 44 & $<0.0005$ \\
\hline \multicolumn{10}{|c|}{ CVD increase, $\%$} \\
\hline $2006-2008$ & 16.67 & 107.14 & 45.45 & 45.45 & 33.33 & 100.00 & 86.84 & 84.21 & \\
\hline $2006-2010$ & 133.33 & 178.57 & 101.52 & 87.88 & 33.33 & 190.00 & 181.58 & 131.58 & \\
\hline
\end{tabular}

\section{Risk Factor Changes between 2004 and 2010}

From 2006 to 2008, the prevalence in 20 different groups by cardiovascular risk factors were all increasing gradient, which were marked as light dark background (See Table 2). For example, in BP groups, the prevalence of men aged from 35 to 49 increased from 45.61 (2006) to 48.00 (2008) and to 50.00 (2010). There were 11 groups had a peak prevalence in 2008, a second higher prevalence in 2006, and a lowest prevalence in 2010, which were marked as a darker background. For example, in BP groups and men older than 80, the prevalence was 62.20 (2008), 60.66 (2006) and 60.55 (2010).From 2006 to 2008, changes in major cardiovascular risk factors together produced a best estimate of 324 deaths increasing in CHD, stroke and PAD, and 502 deaths decreasing in $\mathrm{BP}$ and diabetes (Table 3 and Figure 1). The contribution for the changes above came from the increase in CHD, stroke and PAD, but a decrease in high BP and diabetes.
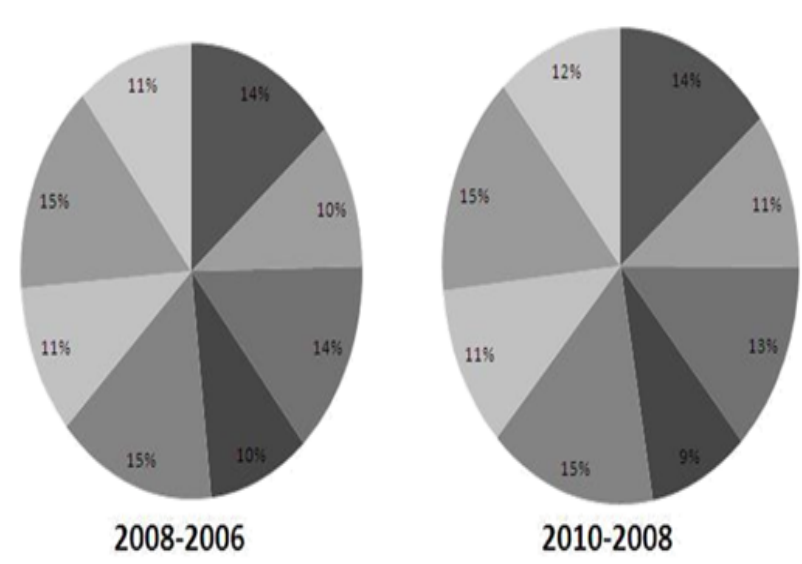

Figure 1: Changes in major cardiovascular risk factors in deaths compared from 2006 to 2008 (left) and 2008 to 2010 (right).

Table 2: Prevalence of CVD in different groups by risk factors.

\begin{tabular}{|c|c|c|c|c|c|c|c|c|c|c|}
\hline \multirow{2}{*}{$\begin{array}{c}\text { Risk } \\
\text { factors }\end{array}$} & \multicolumn{5}{|c|}{ Men } & \multicolumn{5}{|c|}{ Women } \\
\hline & $35-49$ & $50-64$ & $65-79$ & 80 & total & $35-49$ & $50-64$ & $65-79$ & $80 \sim$ & total \\
\hline \multicolumn{11}{|l|}{ BP } \\
\hline 2006 & 45.61 & 51.99 & 58.54 & 60.66 & 56.41 & 43.10 & 55.83 & 63.12 & 63.00 & 60.53 \\
\hline 2008 & 48.00 & 50.88 & 58.44 & 62.20 & 57.12 & 50.00 & 56.07 & 63.96 & 60.92 & 61.21 \\
\hline 2010 & 50.00 & 51.25 & 58.36 & 60.55 & 57.29 & 56.52 & 54.68 & 62.84 & 63.57 & 61.41 \\
\hline \multicolumn{11}{|l|}{ DM } \\
\hline 2006 & 34.21 & 42.39 & 41.58 & 38.36 & 40.71 & 31.03 & 45.56 & 52.60 & 42.73 & 48.51 \\
\hline 2008 & 38.67 & 41.35 & 42.28 & 41.22 & 41.65 & 39.47 & 42.99 & 52.54 & 46.46 & 48.78 \\
\hline 2010 & 38.89 & 42.66 & 29.73 & 29.85 & 42.36 & 26.09 & 41.73 & 52.70 & 49.88 & 49.39 \\
\hline \multicolumn{11}{|l|}{ CHD } \\
\hline 2006 & 28.95 & 29.98 & 29.15 & 22.62 & 28.18 & 5.17 & 13.33 & 21.40 & 18.94 & 18.41 \\
\hline 2008 & 34.67 & 30.83 & 30.13 & 25.61 & 29.41 & 5.26 & 14.33 & 22.08 & 19.08 & 19.29 \\
\hline 2010 & 29.63 & 32.13 & 31.67 & 27.45 & 30.35 & 13.04 & 15.47 & 21.49 & 24.13 & 20.99 \\
\hline \multicolumn{11}{|l|}{ Stroke } \\
\hline 2006 & 8.77 & 12.88 & 28.22 & 38.03 & 24.84 & 15.52 & 13.89 & 30.59 & 53.30 & 29.42 \\
\hline 2008 & 6.67 & 15.04 & 26.61 & 39.02 & 26.01 & 18.42 & 13.40 & 29.19 & 48.31 & 29.69 \\
\hline 2010 & 5.56 & 14.68 & 23.85 & 39.45 & 26.36 & 13.04 & 12.59 & 27.43 & 46.17 & 29.89 \\
\hline \multicolumn{11}{|l|}{ PAD } \\
\hline 2006 & 15.79 & 28.10 & 42.16 & 43.28 & 37.08 & 8.62 & 20.00 & 38.45 & 40.53 & 33.08 \\
\hline 2008 & 14.67 & 28.82 & 41.19 & 46.34 & 38.37 & 10.53 & 18.38 & 38.20 & 42.15 & 34.04 \\
\hline 2010 & 12.96 & 28.25 & 39.35 & 47.45 & 38.78 & 4.35 & 18.71 & 37.57 & 42.92 & 35.05 \\
\hline
\end{tabular}


Table 3: Deaths attributable to population risk factor changes from 2004 to 2010.

\begin{tabular}{|c|c|c|c|c|c|c|c|c|c|c|c|c|c|c|c|c|}
\hline \multirow{2}{*}{$\begin{array}{l}\text { Risk } \\
\text { Factors }\end{array}$} & \multicolumn{4}{|c|}{ Risk factor levels } & \multicolumn{3}{|c|}{ Relative Risk } & \multicolumn{3}{|c|}{ PAR fraction } & \multicolumn{3}{|c|}{$\begin{array}{l}\text { Deaths attributable } \\
\text { to diabetes }\end{array}$} & \multicolumn{3}{|c|}{ Mortality increase } \\
\hline & 2004 & 2006 & 2008 & 2010 & 2006 & 2008 & 2010 & 2006 & 2008 & 2010 & 2006 & 2008 & 2010 & $\begin{array}{l}2008- \\
2006\end{array}$ & $\begin{array}{l}2010- \\
2008\end{array}$ & $\begin{array}{l}2010- \\
2006\end{array}$ \\
\hline \multicolumn{17}{|c|}{ Blood Pressure } \\
\hline Total & 57.66 & 58.32 & 59.01 & 59.20 & 0.97 & 1.18 & 1.17 & 2.58 & 0.91 & 0.91 & 488 & 283 & 394 & -204 & 110 & -94 \\
\hline Men & 55.89 & 56.41 & 57.12 & 57.29 & 0.97 & 1.18 & 1.17 & 2.73 & 0.91 & 0.91 & 324 & 164 & 225 & -160 & 61 & -99 \\
\hline Women & 59.71 & 60.53 & 61.21 & 61.41 & 0.97 & 1.18 & 1.17 & 2.44 & 0.92 & 0.91 & 171 & 119 & 168 & -52 & 49 & -3 \\
\hline \multicolumn{17}{|c|}{ Diabetes } \\
\hline Total & 44.01 & 44.32 & 44.95 & 45.61 & 0.74 & 1.00 & 0.98 & 1.10 & -0.29 & 293.40 & 207 & -90 & $\sim$ & -297 & $\sim$ & $\sim$ \\
\hline Men & 40.42 & 40.71 & 41.65 & 42.36 & 0.74 & 1.00 & 0.98 & 1.11 & -0.26 & -13.69 & 132 & -47 & -3395 & -179 & -3347 & -3526 \\
\hline Women & 48.17 & 48.51 & 48.78 & 49.39 & 0.74 & 1.00 & 0.98 & 1.09 & -0.32 & 12.55 & 76 & -42 & 2309 & -118 & 2351 & 2233 \\
\hline \multicolumn{17}{|c|}{ CHD } \\
\hline Total & 21.67 & 23.66 & 24.72 & 26.01 & 1.71 & 1.28 & 1.16 & 0.94 & 0.87 & 0.80 & 178 & 271 & 346 & 92 & 76 & 168 \\
\hline Men & 26.48 & 28.18 & 29.41 & 30.35 & 1.71 & 1.28 & 1.16 & 0.95 & 0.89 & 0.82 & 113 & 160 & 205 & 47 & 44 & 91 \\
\hline Women & 16.10 & 18.41 & 19.29 & 20.99 & 1.71 & 1.28 & 1.16 & 0.93 & 0.84 & 0.76 & 65 & 110 & 141 & 44 & 31 & 76 \\
\hline \multicolumn{17}{|c|}{ Stroke } \\
\hline Total & 33.78 & 35.23 & 36.36 & 37.06 & 1.58 & 1.52 & 1.54 & 0.95 & 0.95 & 0.95 & 180 & 295 & 412 & 114 & 117 & 231 \\
\hline Men & 35.97 & 37.08 & 38.37 & 38.78 & 1.58 & 1.52 & 1.54 & 0.96 & 0.95 & 0.95 & 114 & 171 & 237 & 58 & 65 & 123 \\
\hline Women & 31.25 & 33.08 & 34.04 & 35.05 & 1.58 & 1.52 & 1.54 & 0.95 & 0.95 & 0.95 & 66 & 123 & 175 & 57 & 52 & 108 \\
\hline \multicolumn{17}{|c|}{ PAD } \\
\hline Total & 26.20 & 26.96 & 27.71 & 28.00 & 2.04 & 2.20 & 2.07 & 0.97 & 0.97 & 0.97 & 183 & 301 & 418 & 118 & 117 & 236 \\
\hline Men & 24.37 & 24.84 & 26.01 & 26.36 & 2.04 & 2.20 & 2.07 & 0.96 & 0.97 & 0.97 & 115 & 174 & 240 & 60 & 65 & 125 \\
\hline Women & 28.33 & 29.42 & 29.69 & 29.89 & 2.04 & 2.20 & 2.07 & 0.97 & 0.97 & 0.97 & 68 & 127 & 178 & 59 & 52 & 111 \\
\hline
\end{tabular}

The biggest contribution for death increasing came from a large increase in PAD prevalence, which led to an estimated 118 additional deaths. The contribution for decrease in the diabetes prevalence was larger than high BP. The contribution for increase in PAD was largest among other three risk factors. In Diabetes, the

death trend was different between men and women. There was a death decreasing in men group but there was a death increasing in women group. In the BP group, there was a special increasing trend in calculation from 2008 to 2010 .

Table 4: Deaths prevented or postponed by medical treatments from 2004 to 2010.

\begin{tabular}{|c|c|c|c|c|c|}
\hline Treatments & drug & patient number & treatment uptake & relative mortality reduction & $\begin{array}{c}\text { CVD Deaths Prevented or } \\
\text { postponed }\end{array}$ \\
\hline \multicolumn{6}{|c|}{ Blood lipid treatment } \\
\hline & Statins & 1181 & 37.2 & 25 & 47 \\
\hline & Fibrates & 92 & 2.9 & 26 & 0 \\
\hline \multicolumn{6}{|c|}{ Hypertension treatment } \\
\hline & ACEI & 1512 & 47.6 & 17 & 53 \\
\hline & ARB & 271 & 8.5 & & \\
\hline & beta-receptor blocker & 1238 & 38.9 & 17 & 35 \\
\hline & $\mathrm{CCP}$ & 1205 & 37.9 & 26 & 51 \\
\hline & Diuretic & 883 & 27.8 & 18 & 19 \\
\hline
\end{tabular}

\section{Medical Treatments}

From 2004 to 2010, the items were different in each visit, especially the drugs in medical treatments. For there were seven drugs both used in 2004 and 2010 see Table 4. We just compared these seven drugs in two years. From 2004 to 2010, medical treatments in individuals together prevented or postponed almost 205 deaths in 2010. Substantial contributions came from treats of ACEI (26\%), CCP (25\%), Statins (23\%), beta-receptor blocker (17\%) and Diuretic (9\%). Due to a few numbers of eligible patients who took Fibrates, there was 0\% DPPs Table 4. Deaths prevented or postponed by medical treatments from 2004 to 2010 


\section{Model Validation}

Table 5 shows the agreement between observed and expected deaths, stratified by gender. Model fit was highest among BP group and DM group and lowest among CHD group, Stroke group and PAD group, which were calculated from 2006 to 2010. From 2008 to 2010, the model fit in BP group was better than other groups.

Table 5: Model validation: estimated vs. observed changes in CVD deaths in Beijing and Shanghai hospital.

\begin{tabular}{|c|c|c|c|c|c|c|c|c|c|c|c|c|c|}
\hline & \multicolumn{3}{|c|}{ CVD death } & \multicolumn{3}{|c|}{ Increase in deaths(2006-2010) } & \multicolumn{3}{c|}{ Increase in deaths (2008-2010) } \\
\cline { 2 - 14 } & $\mathbf{2 0 0 6}$ & $\mathbf{2 0 0 8}$ & $\mathbf{2 0 1 0}$ & $\begin{array}{c}\text { Best } \\
\text { estimate }\end{array}$ & $\begin{array}{c}\text { Mini } \\
\text { estimate }\end{array}$ & $\begin{array}{c}\text { Max } \\
\text { estimate }\end{array}$ & $\begin{array}{c}\text { Model } \\
\text { estimate }\end{array}$ & $\begin{array}{c}\text { model } \\
\text { fit }\end{array}$ & $\begin{array}{c}\text { Best } \\
\text { estimate }\end{array}$ & $\begin{array}{c}\text { Mini } \\
\text { estimate }\end{array}$ & $\begin{array}{c}\text { Max } \\
\text { estimate }\end{array}$ & $\begin{array}{c}\text { Model } \\
\text { estimate }\end{array}$ & $\begin{array}{c}\text { Model } \\
\text { fit }\end{array}$ \\
\hline BP total & 109 & 194 & 270 & 160 & 128 & 192 & 269 & 100 & 73 & 59 & 88 & 267 & 99 \\
\hline men & 68 & 108 & 147 & 103 & 82 & 124 & 171 & 116 & 39 & 31 & 47 & 147 & 100 \\
\hline women & 41 & 86 & 123 & 58 & 47 & 70 & 99 & 81 & 34 & 27 & 41 & 120 & 97 \\
\hline DM & 71 & 139 & 195 & 154 & 123 & 184 & 225 & 115 & 203 & 163 & 244 & 342 & 176 \\
\hline men & 39 & 74 & 102 & 117 & 93 & 140 & 156 & 153 & 124 & 99 & 149 & 198 & 194 \\
\hline women & 32 & 65 & 93 & 43 & 35 & 52 & 75 & 81 & 81 & 65 & 97 & 146 & 157 \\
\hline CHD & 64 & 90 & 123 & 1093 & 875 & 1312 & 1157 & 941 & 600 & 480 & 719 & 690 & 561 \\
\hline men & 40 & 57 & 76 & 527 & 422 & 632 & 567 & 746 & 232 & 186 & 278 & 289 & 380 \\
\hline women & 24 & 33 & 47 & 576 & 461 & 692 & 600 & 1278 & 371 & 297 & 445 & 404 & 859 \\
\hline stroke & 86 & 141 & 199 & 703 & 563 & 844 & 789 & 397 & 409 & 327 & 491 & 550 & 276 \\
\hline men & 57 & 87 & 119 & 412 & 330 & 495 & 469 & 394 & 142 & 113 & 170 & 229 & 192 \\
\hline women & 29 & 54 & 80 & 273 & 218 & 327 & 302 & 377 & 246 & 197 & 296 & 300 & 375 \\
\hline PAD & 79 & 135 & 181 & 621 & 497 & 745 & 700 & 387 & 303 & 242 & 363 & 438 & 242 \\
\hline men & 46 & 79 & 92 & 576 & 461 & 691 & 622 & 676 & 234 & 187 & 281 & 313 & 341 \\
\hline women & 33 & 65 & 89 & 109 & 87 & 131 & 142 & 159 & 98 & 78 & 118 & 163 & 183 \\
\hline
\end{tabular}

\section{Discussion}

The CVD mortality in China has increased dramatically, particularly in urban populations [16]. There were the same trends in the total prevalence in different groups divided by risk factors. Due to medicine treatments, the death rates would not have been even higher.

\section{Prevalence of CVD}

Beijing and Shanghai, two biggest cities in China, had the same increasing trend of prevalence in different age groups. There was a more obvious increase in 50 to 64 age group both men and women, and 65 to 79 age group in women, which were observed in two periods. The first period was from 2006 to 2008 and the second period was from 2006 to 2010. Most of this phenomenon was due to the decline of body function with the increase of age. In the 35 to 49 age group, the men's prevalence of CVD was larger than women's. The reason might be that men had a larger work pressure than women, which was the real situation in China. In Table 1, we found the increase of prevalence rates which showed a smooth negative age gradient in most patients, decreasing from $107.14 \%$ among those aged 50 to 64 years to $45.45 \%$ in those aged more than 80 years, and a similar gradient trend in women patients, with decrease of $100.00 \%, 86.84 \%$ and $84.21 \%$ in the respective age groups. Most of the phenomenon showed the decline of body function, and the relative work pressure. Also, since 2004, there might be no other new patients joined into our cohort.

\section{Risk Factors Changes}

There were increase trends of prevalence in CHD, stroke and PAD, but there were decrease in high BP and diabetes (Table 3). The participants were all patients enrolled in hospitals. The highest increase prevalence was PAD, which could be caused by high calorie, high fat food intake and lack of physical activity and another unhealthy lifestyle. Patients enrolled in this program could take medicine prescribed by doctors to reducetheir blood pressure, blood sugar or blood lipid. This was a good treatment to control their conditions compared with the natural people of those who were sick but do not know they were sick.

\section{Cardiological Treatments}

Due to the dataset was different between the first survey and the following. We just reviewed the DDP by medical treatments between 2004 and 2010, blood lipid treatment and hypertension treatment (Table 4). Medical treatments in individuals together prevented or postponed $\approx 205$ deaths in 2010. Substantial contributions came from blood lipid treatment $(23 \%)$ and hypertension treatment (77\%). Despite the very large numbers of patient taken the medicine,statins, ACEI and CCP prevented more deaths, which reflects the high prescribing levels, however, the opposite situation in Fibrates and ARB treatment.

\section{Limitations of the Data and the IMPACT Model}

There were two main limitations of the data. Firstly, some CVD risk factors were designed in the cross-sectional study in 2004, but 
they were not followed in the following cohort studies from 2006 to 2010. Secondly, compared other IMPACT model applied in China, we analyzed data from our cohort studies other than other sources published by other researchers. However, some data were still available from a variety of sources.

\section{Acknowledgment}

Supported by the National Natural Science Foundation of China (Grant No. 81501203); Supported by Shanghai Key Laboratory of Meteorology and Health (Grant No QXJK201404).

\section{References}

1. Ge L and Ge J (2007)The reasons coronary heart disease mortality has increased in China. The American heart hospital journal 5: 97-99.

2. Jiang G, Wang D, Li W, Pan Y, Zheng W, et al. (2012)Coronary heart disease mortality in China: age, gender, and urban-rural gaps during epidemiological transition. Revistapanamericana de salud publica, Pan American journal of public health 31: 317-324.

3. Guo Y, Li S, Zhang Y, Armstrong B, Jaakkola JJ, et al. (2013) Extremely cold and hot temperatures increase the risk of ischaemic heart disease mortality: epidemiological evidence from China. Heart 99: 195-203.

4. Hu Z, Yuan X, Rao K, Zheng Z and Hu S (2014) National trend in congenital heart disease mortality in China during 2003 to 2010: a populationbased study. The Journal of thoracic and cardiovascular surgery 148: 596-602.

5. Xu M, Guo Y, Zhang Y, Dane W, Yunzheng M, et al. (2014) Spatiotemporal analysis of particulate air pollution and ischemic heart disease mortality in Beijing, China. Environmental health: a global access science source 13: 109.

6. Beaglehole R(1986) Medical management and the decline in mortality from coronary heart disease. British medical journal 292: 33-35.

7. Ebrahim S and Smith GD (2001)Exporting failure? Coronary heart disease and stroke in developing countries. International journal of epidemiology 30: 201-205.
8. Critchley JA and Capewell S (2003)Mortality risk reduction associated with smoking cessation in patients with coronary heart disease: a systematic review. Jama 290: 86-97.

9. Capewell S, Beaglehole R, Seddon M, McMurray J (2000) Explanation for the decline in coronary heart disease mortality rates in Auckland, New Zealand, between 1982 and 1993. Circulation 102: 1511-1516.

10. Capewell S, Morrison CE and McMurray JJ (1999)Contribution of modern cardiovascular treatment and risk factor changes to the decline in coronary heart disease mortality in Scotlandbetween 1975 and 1994. Heart 81: 380-386.

11. Goldman L and Cook EF (1984)The decline in ischemic heart disease mortality rates. An analysis of the comparative effects of medical interventions and changes in lifestyle. Annals of internal medicine 101: 825-836.

12. Hunink MG, Goldman L, Tosteson AN, Mittleman MA, Goldman PA, et al. (1997) The recent decline in mortality from coronary heart disease, 1980-1990. The effect of secular trends in risk factors and treatment. Jama 277: 535-542.

13. Unal B, Critchley JA and Capewell S (2004) Explaining the decline in coronary heart disease mortality in England and Wales between 1981 and 2000. Circulation 109: 1101-1107.

14. Critchley J, Liu J, Zhao D, Wei W, Capewell S (2004)Explaining the increase in coronary heart disease mortality in Beijing between 1984 and 1999. Circulation 110: 1236-1244.

15. MacIntyre K, Capewell S, Stewart S, Chalmers JW, Boyd J, et al. (2000) Evidence of improving prognosis in heart failure: trends in case fatality in 66547 patients hospitalized between 1986 and 1995. Circulation 102: 1126-1131.

16. Wu Z, Yao C, Zhao D, Wu G, Wang W, et al. (2001)Sino-MONICA project: a collaborative study on trends and determinants in cardiovascular diseases in China, Part i: morbidity and mortality monitoring. Circulation 103: $462-468$.

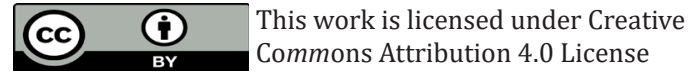

Submission Link: https://biomedres.us/submit-manuscript.php

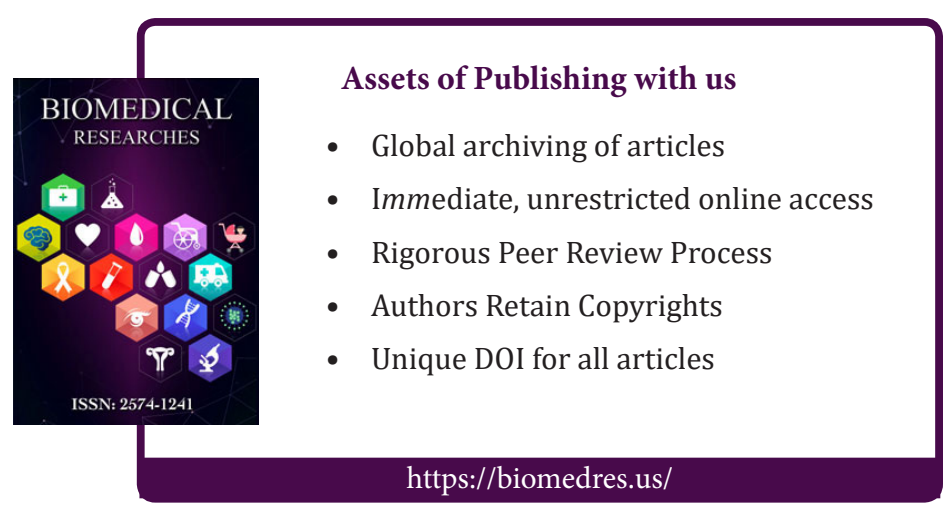

